\title{
Analisis Data Gaya Berat dan VLF untuk Penentuan Bidang Patahan Penyebab Semburan Lumpur di Sumur Eksplorasi BJP-1 Porong
}

\author{
Seno Pudji Sardjono* \\ Staf pengajar Program Studi Geofisika FMIPA ITS \\ Prihadi \\ Staf pengajar Jurusan Teknik Geologi ITB
}

\begin{abstract}
Intisari
Semburan lumpur panas disertai gas hidrokarbon telah terjadi di sumur eksplorasi migas Banjar Panji 1 (BJP1) Porong Sidoarjo Jawa Timur pada tanggal 29 Mei 2006. Terdapat tiga titik semburan pada posisi segaris, pada salah satu titik semburan hingga saat ini terus mengeluarkan lumpur panas dengan debit $150.000 \mathrm{~m}^{3} / \mathrm{hari}$. Keluarnya lumpur dari tiga titik segaris mengindikasikan lumpur keluar dari bidang lemah bukan dari lubang eksplorasi. Untuk membuktikan indikasi adanya semburan lumpur yang keluar dari bidang patahan digunakan teknik geofisika yaitu dengan metoda gaya berat dan VLF (Very Low Frequency). Metoda gaya berat dilakukan pada 200 titik ukur seluas $6 \mathrm{~km}^{2}$ sedangkan untuk metoda VLF menggunakan 4 lintasan dengan panjang antara $2-7 \mathrm{~km}$ yang jarak antar pengukuran $10 \mathrm{~m}$. Hasil analisis kedua metode tersebut menunjukkan adanya patahan sepanjang $7 \mathrm{~km}$ yang memanjang dari Barat Daya-Timur Laut memotong ketiga titik semburan lumpur. Dari data geologi kuarter daerah Porong maka patahan tersebut berkorelasi dengan patahan Watukosek yang memanjang dari gunung Penanggungan hingga Bangkalan Madura.
\end{abstract}

KATA KUNCI: semburan lumpur, gaya berat, VLF

\section{PENDAHULUAN}

Pada tanggal 29 Mei 2006 telah terjadi semburan lumpur panas di sekitar sumur eksplorasi migas Banjar Panji 1 (BJP1), Porong Sidoarjo Jawa Timur. Ada tiga titik semburan lumpur yaitu pada posisi 7031 ' 40,5" LS - 1120 42' 23,34" BT, 70 31' 33,72' LS - 1120 42' 47,34"'BT dan 70 31' 28,92" LS - 1120 42' 55,74” BT (Gambar 1). Ketiga titik semburan lumpur tersebut terletak di desa Siring dan desa Renokenongo, Porong Sidoarjo.

Ketiga titik semburan lumpur apabila diproyeksikan akan berada pada sebuah kelurusan dengan arah Barat Daya-Timur Laut. Kondisi seperti ini memunculkan hipotesa bahwa semburan lumpur di sekitar sumur BJP-1 merupakan semburan lumpur yang keluar dari bidang patahan bukan melalui lubang. Untuk membuktikan hipotesa tersebut maka dilakukan investigasi geofisika dengan metoda gaya berat dan VLF (Very Low Frequency) di sekitar sumur eksplorasi migas BJP-1 .

${ }^{*}$ E-MAIL: senopudji@hotmail.com

\section{METODA GAYA BERAT DAN VLF}

Hingga saat ini lebih dari 40 titik semburan gas yang terjadi di sekitar sumur eksplorasi migas BJP-1 Porong Sidoarjo selain dari titik semburan utama yang menghasilkan lumpur panas. Melihat sebaran semburan gas dan lumpur panas yang berorientasi pada bidang lemah (atau bidang patahan) tertentu maka dilakukan investigasi geofisika dengan metoda gaya berat dan VLF untuk membuktikan hipotesa tersebut.

Metoda gaya berat telah digunakan oleh Kadirov [1] untuk memetakan kondisi bawah permukaan di mud volkano Lokbatan Azerbaijan. Krocker [2] menggunakan metoda gaya berat untuk interpretasi bawah permukaan di mud volcano Haakon Mosby. Secara umum bidang patahan dapat dideteksi dengan metoda gaya berat secara regional [3-5]. Pada dasarnya metoda gaya berat akan menunjukkan anomali percepatan gaya berat di permukaan apabila terdapat ketidakhomogenan struktur di bawah permukaan bumi. Patahan menyebabkan struktur bawah permukaan bumi mengalami ketidakhomogenan massa pada daerah tertentu yang menyebabkan perubahan gaya berat terukur di permukaan bumi. Pengukuran gaya berat dilakukan pada 200 titik amat pada luasan $6 \mathrm{~km}^{2}$ di sekitar sumur eksplorasi BJP-1 pada bulan Juni 2006.

Karena kandungan $\mathrm{NaCl}$ yang sangat tinggi maka lumpur Porong mempunyai konduktifitas yang sangat tinggi pula dibandingkan dengan lingkungan sekitarnya. Kondisi ge- 


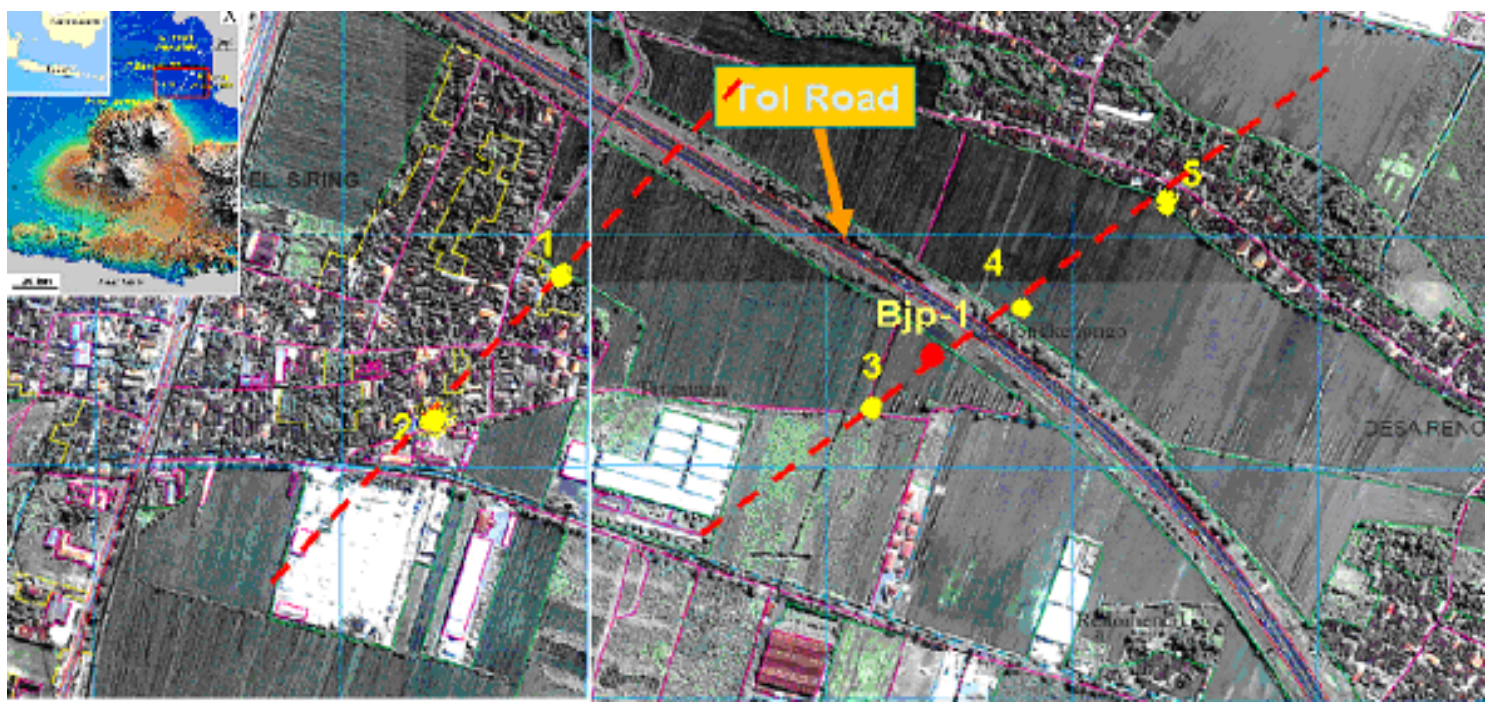

Gambar 1: Posisi semburan lumpur di sumur eksplorasi BJP-1 Porong Jawa Timur.

ologi dengan kemungkinan struktur patahan dan konduktifitas seperti inilah yang kemudian dilakukan pemilihan metoda geofisika VLF untuk investigasi. Pada prinsipnya metode VLF adalah metoda yang menggunakan gelombang elektromagnetik (EM). Gelombang elektromagnetik primer yang dipancarkan oleh transmiter akan diterima oleh receiver secara bersamaan [3-6]. Apabila di dalam bumi ada material yang bersifat lebih konduktif dari lingkungannya maka terjadi perbedaan fase antara gelombang EM primer dan sekunder [7-9]. Pengukuran dengan metoda VLF dilakukan pada 4 lintasan dengan panjang lintasan antara 3 hingga $6 \mathrm{~km}$ serta interval titik pengukuran $10 \mathrm{~m}$ pada bulan Juni 2006.

\section{ANALISIS DATA GAYA BERAT DAN VLF}

Data gaya berat yang diperoleh adalah data gaya berat anomali Bouguer yang terletak pada bidang air laut rata-rata (MSL). Anomali gaya berat menunjukkan adanya dua kutub anomali yaitu anomali negatif pada daerah di sekitar sumur BJP-1 dengan harga minimum sekitar 0,68 mgal, sedangkan $500 \mathrm{~m}$ di Timur Laut BJP-1 terdapat anomali maksimum berharga $0,63 \mathrm{mgal}$ (Gambar 2). Anomali negatif gaya berat ini terjadi karena adanya kemungkinan amblesan di sekitar sumur BJP-1 (Gambar 1) akibat adanya semburan lumpur selain juga berkorelasi dengan adanya material lumpur di sekitar BJP-1 yang mempunyai rapat massa lebih kecil dari pada batuan sekitar (Gambar 4). Amblesan di daerah sekitar sumur BJP-1 bersifat dangkal dan berbentuk konsentris relatif ke arah pusat semburan.

Data VLF yang ditampilkan adalah data beda fase antara gelombang primer dan sekunder setelah melalui pemfilteran dengan metoda Karaous-Hjelt. Beda fase terlihat antara -300 hingga 600 pada ke empat lintasan yang menunjukkan adanya bidang patahan yang terjadi secara vertikal ke bawah hingga kedalaman 500 m (Gambar 3(a)). Apabila keempat lintasan tersebut digabungkan dalam suatu peta regional maka patahan

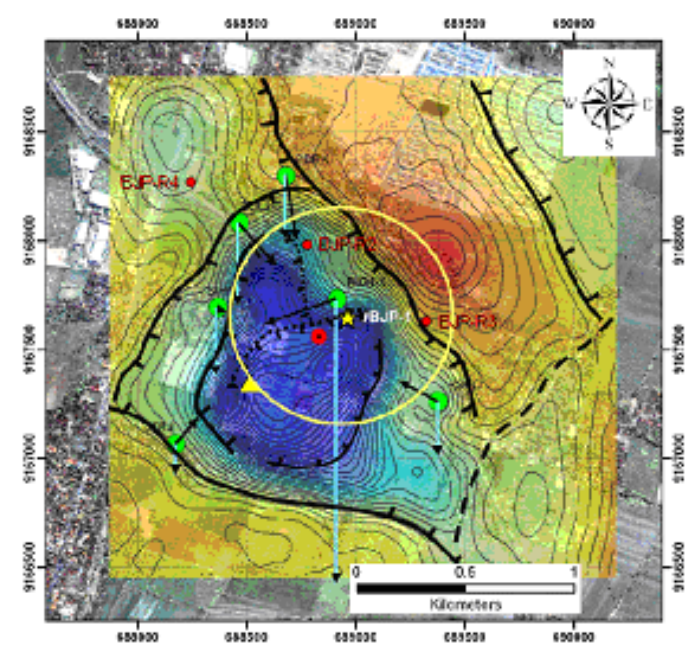

Gambar 2: Anomali gaya berat di sekitar sumur BJP-1, Garis hitam menunjukkan patahan dangkal akibat amblesan.

ini berarah N 450 E (Gambar 3(b)). Patahan ini dalam referensi geologi kuarter yang disebut sebagai patahan Watukosek. Patahan ini memanjang dari Gunung Penanggungan hingga ke arah Bangkalan Madura.

Jadi diyakini bahwa semburan lumpur panas yang terjadi di sekitar sumur eksplorasi BJP-1 keluar dari suatu bidang lemah yang dalam hal ini adalah patahan/sesar Watukosek, sedangkan sesar dangkal yang bersifat konsentris di sekitar sumur BJP-1 disebabkan oleh adanya amblesan akibat perubahan porositas di bawah permukaan karena keluarnya massa batuan bawah permukaan. 

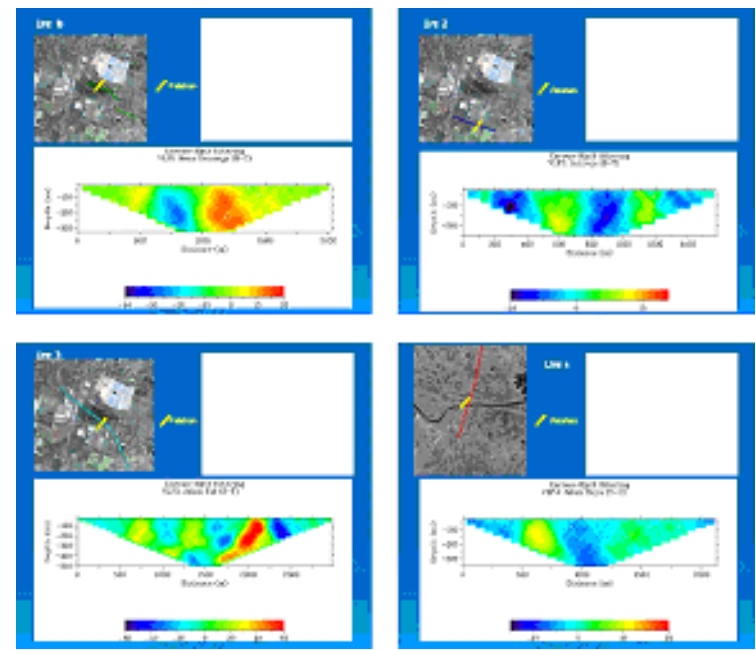

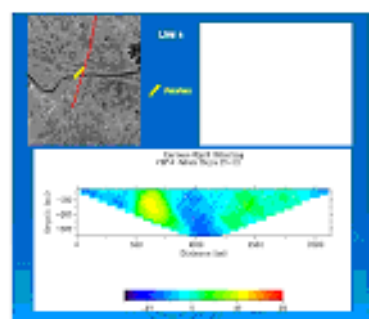

(a)

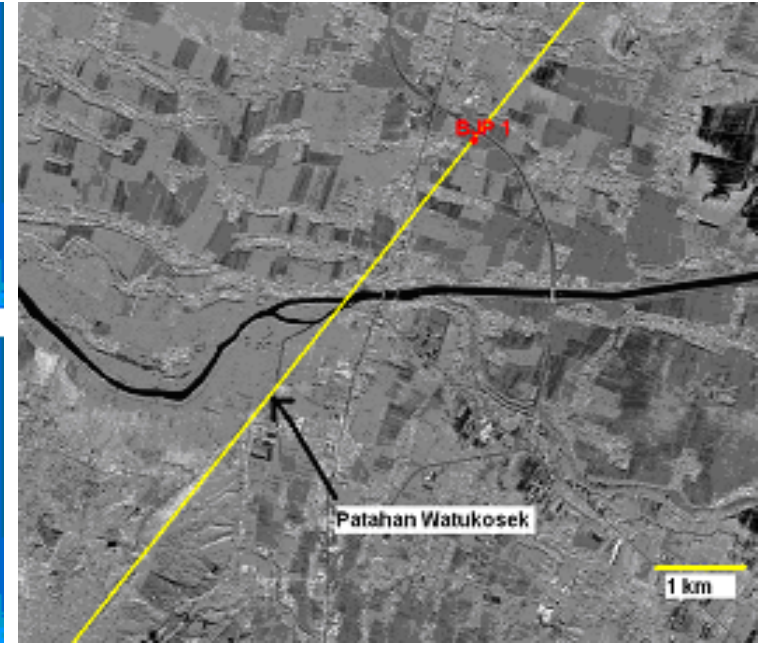

(b)

Gambar 3: (a). Beda fase yang terjadi pada empat lintasan metoda VLF yang menunjukkan adanya patahan dengan kedalaman hingga 500 $\mathrm{m}$,(b).Patahan Watukosek dengan arah N 450 E yang berimpit dengan sumur BJP-1.

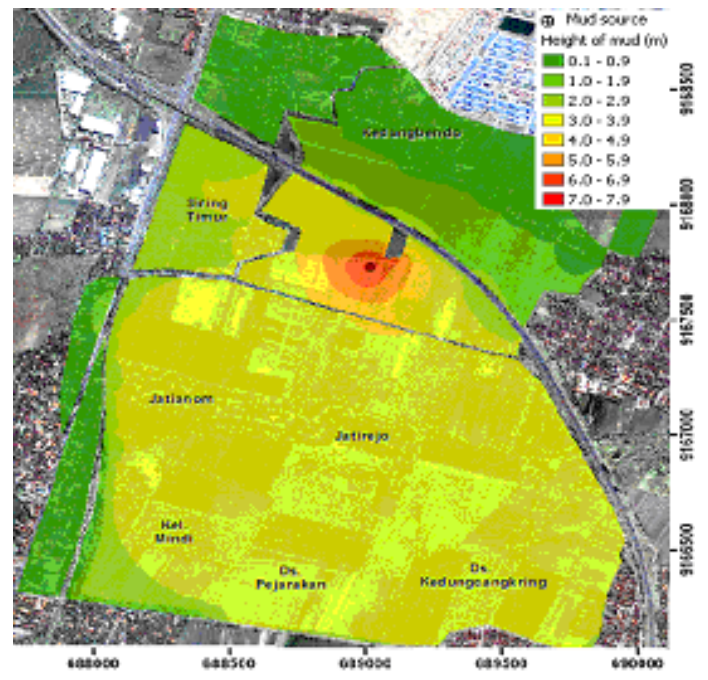

Gambar 4: Tebal endapan lumpur di sekitar sumur eksplorasi BJP-1 (Juli 2006).

\section{SIMPULAN}

Dari analisis di atas dapat diambil kesimpulan bahwa dengan metoda VLF dapatlah diketahui bahwa semburan lumpur panas di sekitar sumur eksplorasi BJP-1 terletak pada patahan Watukosek. Sedangkan dengan metoda gaya berat didapatkan adanya struktur patahan dangkal berbentuk konsentris terhadap titik semburan lumpur yang dipotong oleh sesar Watukosek. Patahan dangkal ini disebabkan oleh adanya penambahan porositas akibat massa batuan yang keluar menuju permukaan. .
[1] Kadirov, F.A., A.H. Kadyrov, dan S.G. Mamadoy., Gravitational Field Dated for Mud Volcanos - on the Example of Lokbatan Volcano, Azerbaijan, Prosiding. 66th EAGE Conference and Exebition. Paris, (2004)

[2] Krocker, R., Beyer A., Rathlau R., Schenke H.W., Haakon Mosby Mud Volcano: Marine Gravity Data. Prosiding EGU General Assembly. Nice (2004).

[3] Dobrin, M., 1988. Introduction to Geophysical Prospecting. McGraw Hill. New York.

[4] Reynolds, J.M., An Introduction to Applied and Environmental Geophysics, John Wiley \& Sons. New York (1997).

[5] Telford, W.M., L.P. Geldard, R.E. Sheriff dan D.A. Keys, Applied Geophysics. Cambridge University Press. Cambridge
(1990).

[6] Ward, S.H., Electrical, Electromagnetik, and Magnetotelluric Methods, Geophysics, vol. 45, hal. 1659-1666 (1980).

[7] Aqies, R., S.P. Sardjono, D. Santoso, dan M.I.T. Taib, Interpretasi Bawah Permukaan Surabaya dengan Menggunakan Metoda $V L F-R$, Prosiding PIT HAGI ke 27. Batu (2002).

[8] Benson, A.K., K.L. Paine, dan M.A. Stubben, Mapping Groundwater Contamination Using DC Resistivity and VLF Geophysical Methods - A Case Study, Geophysics, 62, 80-86 (1997).

[9] McNeill, J.D., Use of Electromagnetik Methods for Groundwater Studies, dalam Geotechnical and Environmental Geophysics I, hal 191-218. SEG. Tulsa (1990). 